\title{
Gitanos i paios. El llarg camí del reconeixement $\mathbf{i}$ del respecte mutu Mutual recognition as a normative basis of intercultural encounter
}

Als mens amics els oncles Manel, de Gràcia (Barcelona); «Ninorro», de Mataró; Ángel, de Vilanova; Joan, de Reus; Àngel, de Manresa; Antonio, de Lleida, i Enric, de Castelló, mestres de vida i pedagogs de la memòria collectiva dels gitanos catalans.

\section{Resum}

Els gitanos són una minoria present fa sis segles a Europa. Avui vindiquen el seu lloc en la construcció d'una Europa plural, respectuosa amb les seves minories i sense discriminacions per raó d'ètnia i origen. En la construcció de l'Europa del segle xxi s'ha de comptar amb ells. Tenen una cultura discernible, versàtil, adaptatícia, resistent i resilient. Són una cultura heterogènia, amb una identitat ètnica compartida i difusa. Avui les institucions la reconeixen però, sovint, socialment i política, és qüestionada o rebutjada. La superació dels conflictes culturals existents, només serà possible amb el diàleg intercultural, l'exercici del respecte mutu i una gran paciència històrica.

Paraules clau: cultura gitana, minoria ètnica gitana, diàleg intercultural.

\begin{abstract}
The Roma are a minority present for six centuries in Europe. Today we claim its place in building a pluralistic Europe, respectful of its minorities, without discrimination on grounds of ethnicity and origin. In the construction of the XXI century Europe has to have them. They have a discernible culture, versatile, adaptable and resilient. They are a diverse culture with a shared ethnic identity and diffuse. Today the institutions recognized it but, often, socially and politically, is questioned or denied. Overcome existing cultural conflict is only possible to intercultural dialogue, mutual exercise and great historical patience.
\end{abstract}

Keywords: gypsy culture, gypsy ethnic minority, intercultural dialogue.

Els gitanos són una minoria ètnica en les nostres societats i un poble conformat històricament i social per una llengua i una cultura, amb una voluntat inequívoca d'ésser, perquè no vol morir. Un poble, en definitiva, amb senyes pròpies d'identificació, diferenciat d'altres amb què conviu i comparteix la comuna ciutadania europea i la respectiva nacionalitat. És així des de fa segles. 


\section{Una ciutadania europea indiscutible però qüestionada}

La presència dels gitanos a l'antiga Corona d'Aragó data de 1425. Es van presentar com a peregrins, camí de Santiago de Compostela, per aconseguir els guiatges que els permetrien transitar pels regnes de la Corona amb llibertat. Si, com insinuava Goethe, la consciència d'Europa va néixer amb les peregrinacions medievals, els gitanos estan presents en el procés de construcció europea des del principi. Ben aviat serien objecte de persecució i, més endavant, d’intents de genocidi, amb períodes intermitents de tolerància o assimilacionisme a la societat majoritària, fins ben entrat el segle xx. Aquesta història agitada i dura ha marcat la cultura gitana a tot Europa. També els gitanos s'han vist davant de «monstres i paranys», i han reaccionat «empal.lidits per la seva audàcia», i han esdevingut «la joguina d'una imatge», d'un estereotip segregador $\mathrm{i}$ amb connotacions racistes, que els ha perseguit fins als nostres dies. Aquestes expressions entrecomillades d'Horaci sobre Europa (Oda a Galatea) són aplicables plenament als gitanos. Al llarg d'un dilatat període històric, ple de vicissituds de tota mena, els gitanos han viscut canvis profunds en la seva vida, i s'han adaptat als diferents entorns socials i polítics amb els quals s'han trobat.

La tradició cultural gitana ens parla de continguts culturals concrets i d'una identitat resistent i durable, amb una indomable voluntat col-lectiva de continuar existint com a gitanos, més enllà de condicions socials, orígens i formes determinades de vida. Tenen llengua pròpia, avui en procés de recuperació incipient i de normalització, i símbols d'autoreferència; han viscut un conflicte continuat amb el poder establert $\mathrm{i}$ han aplicat estratègies d'adaptació o acoblament i de supervivència, basades en una capacitació múltiple i poc especialitzada; tenen una organització social flexible i, alhora, molt rígida en la vida quotidiana del grup; una autonomia per a cada grup, amb principis interns de jerarquització i amb preponderància masculina d'edat i de la relació pare-fill sobre qualsevol altre lligam. Com ja hem dit, la cultura gitana és resistent: tant al poder com a l'escassetat i a la precarietat d'alternatives.

La cultura gitana és, a més, heterogènia i diversa: «Tots som gitanos, però no tots els gitanos som iguals». Els gitanos tenen una identitat cultural col-lectiva compartida però dotada d'una certa imprecisió capaç de sobreviure en contextos socials molt diferenciats i d'adaptar-se en una o altra direcció o en la contraria, si s'escau, sense deixar d'ésser ella mateixa; capaç d'adoptar una imatge o color segons imposin les circumstàncies, sense, per això, perdre els trets identitaris propis. Un gitano ens deia gràficament: «És molt relatiu parlar dels gitanos en general (...). És important distingir entre allò que és pròpiament gitano i el que és conseqüència d'altres circumstàncies: hi ha molta confusió». La seva ha estat, i segueix essent, una cultura discernible però versàtil i amb una notable capacitat d'adaptació a l'entorn, com ja s’ha dit. Són una minoria heterogènia, amb una identitat ètnica compartida i difusa.

M'atreviria a dir que els gitanos se senten, per sobre de tota altra consideració, ciutadans del món. La seva bandera té el verd de la terra, el blau del cel i la roda del carro, 
que simbolitzen el seu universalisme i els seus orígens nòmades. Els gitanos se senten ciutadans sense fronteres, tot i que estan i se senten ben arrelats als territoris en què viuen. La seva pàtria gran és el món. Són gitanos per ascendència, autoidentificació i reconeixement de la pròpia comunitat gitana. Tenen una cultura (la roma) i una llengua pròpia (el romanó). D’origen indi, els gitanos que viuen a Europa són, en opinió de molts, europeus i transnacionals de projecció. Constitueixen la minoria ètnica més vulnerable d'Europa i aspiren i reivindiquen, avui com mai, la seva plena ciutadania. ${ }^{1}$

En l'article I.2 del nou projecte de Tractat de la Unió Europea que establia una non nata Constitució Europea (2004) es deia que:

«la Unió es fonamenta en els valors de respecte a la dignitat humana, la llibertat, la democràcia, la igualtat, l'Estat de Dret i el respecte dels drets humans, incloent-hi els drets de les persones que pertanyen a minories. Aquests valors són comuns als Estats membres, en una societat caracteritzada pel pluralisme, la no discriminació, la tolerància, la justícia i la igualtat entre dones i homes».

La redacció d'aquest article, en la seva literalitat, millorava i completava el vell redactat del punt I.1 de la Declaració sobre la identitat europea, signada pels dirigents dels nou estats integrants de la Comunitat Econòmica Europea, el mes de desembre de 1973. Per als gitanos, com a minoria que són, el reconeixement de la ciutadania europea sobre aquests fonaments era una molt bona notícia.

Els gitanos són presents a Europa des del segle XIV i es pot afirmar que fins al segle xx no han vist explícitament reconeguda la seva ciutadania com a europeus i membres dels estats que integren l'actual Unió Europea. En el cas espanyol, el Parlament de Catalunya va donar un primer pas en la línia d'aquest reconeixement quan, el 21 de novembre de 2001, «la identitat del poble gitano i el valor de la seva cultura» $\mathrm{i}$ instava a difondre «el reconeixement de la seva cultura i del valor d'aquesta per a la societat catalana».

Tenia raó Gunter Grass quan deia que els gitanos «viuen a tots els països d'Europa, no miren fronteres, no volen un estat $\mathrm{i}$ han contribuït molt a la nostra cultura. Els gitanos són els vertaders europeus! Tenim molt a aprendre dels gitanos. Són l'ànima d'Europa». ${ }^{2}$ Una bona part d'aquest poble té, ben entrat el segle XxI, una autentica oportunitat històrica i, com sempre, viu un present ple d'inseguretat, incertesa i, massa sovint, de marginació i d'exclusió social. S’està produint una clara paradoxa: per una banda, s'avança en el reconeixement institucional de la comunitat gitana a Europa i Espanya, en el marc de noves mesures per a la protecció de les

1 San Román, T. (1994): La diferència inquietant. Barcelona: Fundació Serveis Cultura Popular- Alta Fulla, pp. 141 - 146 Garriga, C. i Carrasco, S. (2003): Els gitanos de Badalona. Diputació de Barcelona; Barcelona,pp.29-39.

Aguirre Felipe, Javier (2006): Historia de las itinerancias gitanas. De la India a Andalucía. Institución Fernando el

Católico. Diputación de Zaragoza.

2 Grass G.: Los gitanos son los verdaderos europeos. La Vanguardia, 31. 03. 04. 
minories ètniques, promogudes al llarg dels darrers vint anys, i, per l'altra, es viuen fets gravíssims de racisme i discriminació envers comunitats gitanes a molts països europeus. $^{3}$

\section{Tres dècades de lluita contra el racisme i la xenofòbia}

L'any 1990, el Parlament Europeu alertava, a tres anys de l'entrada en vigor del mercat comú europeu, sobre l'avenç de la xenofòbia i el racisme de l'extrema dreta europea. En l'informe d'aquell any, una comissió especial, presidida per l'eurodiputat Glyn Ford, advertia sobre la gravetat de fets racistes i xenòfobs neonazis a la Comunitat Europea, tot remetent a l'Informe Evrigenis del 1986. En els darrers vint anys, l'activisme racista ha anat avançant i sembla haver-ho fet de manera força general. Des dels anys 1990, els informes sobre aquesta qüestió s'han anat succeint a les institucions de la Unió Europea, al Parlament Europeu i al Consell d'Europa. Citem, a tall d'exemple, la Comunicació de les Comunitats Europees sobre el racisme, la xenòfobia i l'antisemitisme amb la Proposta de Decisió del Consell per la qual es declarava 1997 Any Europeu contra el Racisme. I també una de les darreres manifestacions institucionals d'aquests tipus, com la Declaració d'Estrasburg del Consell d'Europa, del 20 d'octubre de 2010, en la qual es condemnava, per unanimitat, la discriminació generalitzada contra els gitanos i la seva marginació social i econòmica. Aquesta Declaració recomana, entre d'altres accions, dels drets dels infants gitanos; la garantia d'un accés igual i efectiu als sistemes judicial i sanitari; la lluita contra la incitació al discurs racista; la instauració de mesures d'inclusió social en el camp de l'educació, de l'ocupació i la formació professional; la garantia de l'accés igualitari als serveis d'habitatge i allotjament; el foment del coneixement $\mathrm{i}$ l'enteniment de la cultura, la història i la llengua gitanes. ${ }^{4}$

La relectura dels textos clàssics sobre l'evolució de la consciència europea, recollits per G. Reynold (1944) i D. Rougemont (1961) o els llibres de G. Steiner (2004), J. Fontana (1994) o E. Morin (2003), per citar alguns autors, ${ }^{5}$ corroboren les conno-

\footnotetext{
3 Fundación Secretariado Gitano (2006): El reconocimiento institucional de la comunidad gitana en España. Madrid. Colección de Cuadernos Tecnicos, núm. 57.

El Parlament de Catalunya donaria el primer pas important, en la línia que suggerim, quan el 21 de novembre de 2001, reconeixia «la identitat del poble gitano i el valor de la seva cultura» $\mathrm{i}$ instava a difondre «el reconeixement de la seva cultura i del valor d'aquesta per a la societat catalana».

Veure, també, M.Flasiková-Benová; Hannes Swoboda; Jan Marinus Wiersma (eds.).

-(2011) Roma: A European Minority: The Challenge of Diversity. Group of the Progressive Alliance of Socialists and Democrats.

4 Bruselas, 13.12.95. COM (95) 653 final.

Salvador Carrasco i Carme Garriga: Noves realitats, nous reptes $i$ vells problemes pendents. SOS Racisme-Catalunya. Informe Anual 2010.

5 Reynold, G. (1944): La formation d'Europe. Friburg: Egloff.

Rougemont, D. (1961): Vingt-buit sièules d'Europe. Paris: Payot.

Steiner, G. (2004): La idea d' Europa. Barcelona; Arcadia.

Fontana, J. (1994): Europa ante el espejo. Barcelona:Crítica.

Morin, E. (2003): Pensar Europa. La metamorfosis de un continente. Barcelona: Gedisa.
} 
tacions europees de la cultura gitana: una i diversa; resistent i adaptatícia; feta i refeta en el conflicte; universalista i fidel a una determinada identitat col-lectiva; amant de la llibertat i aferrada a tradicions culturals centenàries; fidel a si mateixa i immersa en processos històrics de canvi social, cultural i polític, com no s'han viscut abans, que els porten a qüestionar la pròpia identitat de manera permanent.

La història dels gitanos europeus és la d'un poble mil·lenari, la d'una minoria, present fa sis segles a Europa, que reclama avui el seu lloc en la construcció d'una Europa plural, respectuosa de les seves minories i sense cap mena de discriminació per raó d'ètnia i orígens. En la construcció de la nova ciutadania europea s'ha de comptar amb aquesta minoria cultural, europea per tots els cantons pels que es vulgui mirar, més enllà de tòpics i els estereotips dominants.

\section{Resistència, resiliència $i$ convivència intercultural}

Els gitanos són poc coneguts i, sovint, segurament a causa d'aquest mateix desconeixement, el poc que se'n sap es tenyeix de tòpics i estereotips malauradament molt estesos. Molts dels seus conciutadans no sempre reconeixen la presència de gitanos, tot i que mantenen genuïnament la seva identificació com a gitanos. En aquest sentit, la distinció entre identitat i continguts ètnics és altament significativa. Són molts els gitanos que han aprofitat les oportunitats existents per a fer una plena inserció en la vida social. Als ulls de molts altres gitanos, s'han «apaiat» (és a dir, tenen formes de vida no gitanes) $i$ als ulls de molts de nosaltres, esdevenen invisibles com a gitanos. I són, tant o més que per la seva invisibilitat, perquè tendim a no reconèixer com a gitanos més que als marginats i als que s'han adaptat a l'exclusió social o els que confirmen els estereotips negatius.

Al llarg del temps, els gitanos han implementat diverses estratègies exitoses de supervivència. La seva és una cultura resistent i resilient, amb forta capacitat i habilitat d'enfrontar-se, amb actituds positives i proactives, a situacions adverses i de crisi, i durable, tramesa de pares a fills. La família és l'eix estructurant bàsic de la vida social dels gitanos. La vida sencera del gitano gira a l'entorn de la familia.

Han resistit, durant segles, davant del poder, l'escassetat i la precarietat d'alternatives, adaptant-se en funció de les possibilitats de cada situació històrica, conservant una clara memòria col·lectiva del que van viure els seus avantpassats, aprenent d'un passat ple de dificultats que els ha ensenyat a acoblar-se amb la població majoritària sense renunciar a una potent identificació ètnica. Aquest poble ha après a doblegar-se sense trencar-se i sense perdre les seves arrels, com els joncs a la vora dels rius. Avui, entre nosaltres, els gitanos vindiquen la seva plena ciutadania europea i, alhora, mantenen una identitat col-lectiva diferenciada. 
Són i se senten ciutadans de ple dret, amb la riquesa afegida de la seva «gitanitat» (romipen). De vegades, posen a prova valors i formes de vida dominants en la societat majoritària. Com en tota convivència cívica, els gitanos també tenen problemes i situacions compromeses entre ells $i$ amb els paios que els envolten. Aquesta minoria ha estat enquadrada, històricament i de manera majoritària, entre els estrats socials més baixos de les societats europees. En expressió de Ferran Soldevila, els gitanos ocupaven, majoritàriament, en l'escala social i durant l'edat moderna, el graó anterior al dels esclaus. ${ }^{6}$ Són relativament pocs els que van ocupar i ocupen posicions socials més elevades. En els nostres temps alguns d'ells han practicat una forta militància ètnica.

\section{«Memòria de futur»}

La memòria d'aquest poble és singular, com els fets que configuren un passat, fet de l'afirmació d'una identitat ètnica a la qual no han renunciat de cap manera al llarg dels sis segles de presència a la península. Tenen una cultura provada per la persecució i la marginalitat.

Han sobreviscut a intents de genocidi, com el de l'Espanya de Ferran VI o el porrajmos (l'«abolició de gitanos» pels nazis en els camps d'extermini). Només a Espanya, entre 1499 i 1783, es van promulgar més de 250 providències antigitanes.

Estan per aplicar-se als gitanos aquella sociologia i pedagogia de la Memòria que dóna comptes i explica com la memòria col-lectiva permet a un poble reviure i recordar els esdeveniments en el marc social en què es van produïr. Els gitanos transmeten la història del seu passat de maneres diverses, referides a la vida individual, grupal i social amb un llenguatge senzill, plagat d'anècdotes. És una memòria social, exemplar, que es transmet de pares a fills, continguda en la saviesa dels seus «vells» (persones de respecte en la comunitat) a través dels quals segueixen vives «les ensenyances dels nostres avantpassats»: hi convergeixen i s'hi reflecteixen les expectatives i els desitjos, els interessos, l'afectivitat, l'autocomprensió del grup, els èxits i les dificultats familiars dels diferents tipus de gitanos. La referència a Maurice Halbwachs i Gérard Namer en aquest punt es fa ineludible. ${ }^{7}$

La memòria a què ens referim parla per si mateixa, conté «missatge»: manifesta amb eloqüència elements identitaris i es dirigeix a la comunitat, a les noves generacions, i a qui sigui receptiu a la significació d'uns fets referits a «un temps situat en el cor del grup», ni passat, ni present, ni futur «un presente transtemporal», un present del passat $\mathrm{i}$ un present del futur. Un bon amic gitano em comentava, no fa

6 Soldevila, F. (1995): Historia de España (vol. 2,).Barcelona: Crítica; pàg. 312.

7 Halbwachs, M. (1997): La mémoire collective. París, Albin Michel.

Namer, G. (1987): Mémoire et societé. París, Méridiens Klincksieck.

Sobre la pedagogia de la memòria: Torner, C. (2002): Shoah. Una pedagogia de la memòria. Barcelona, Proa. 
gaires mesos que «nosaltres mirem el temps com present». Sabem que la concepció i l'organització del temps és un element capital de la vida social. ${ }^{8}$ En aquest punt (per raons històriques no podria ser d'una altra manera) els gitanos han tingut històricament valoracions i maneres d'entendre l'ús del temps i l'ocupació de l'espai molt diferents de les de la societat majoritària. Algunes de les dificultats de la convivència intercultural deriven de les concepcions divergents en aquestes materies.

La memòria col-lectiva dels gitanos és, també, selectiva, problemàtica, inacabada i plural; és un instrument al servei de la lluita per la vida, en l'arena de la confrontació d'interessos socials; està centrada en esdeveniments, figures i situacions que ensenyen a viure com a bons gitanos, a conèixer i respectar la llei gitana, a ser éssers humans dignes d'aquest qualificatiu, a evitar les trampes i els paranys que poden posar en perill la famiília i el grup. Està primordialment orientada a la continuïtat $i$ la supervivència del grup familiar i del conjunt dels gitanos i a la pervivència i preservació de la seva cultura. El racisme és, alhora, un llast i un incentiu que manté viva la memória col-lectiva de la qual parlem.

Amb Teresa San Román, distingim entre actituds, conductes i ideologia racistes. ${ }^{9}$ El racisme té, almenys, aquestes tres dimensions, que fan referència a components diversos (opinions i expressions; actes excloents; representacions d'un imaginari i idees discriminatòries) i tenen resultats, també, diferents (foment de sentiments hostils; agressions; discriminació o abús d'allò diferent, de les minories).

El racisme, com a ideologia, ha legitimat abusos i formes de discriminació i marginació injustificables d'una altra manera. El racisme ha ofert, un cop més, la justificació a la injustícia, a la insolidaritat i als que neguen la diversitat des de les vísceres.

De fet, com ha estat sempre, els que queden fora dels circuïts econòmics, de la participació i de la informació reconeguts socialment, segueixen essent els mateixos. Entre ells, és clar, la minoria gitana europea. Manllevant el vers de Carles Torner, jove poeta català, diem que «contra la por, la veritat del crit». El nostre no pot deixar de ser un crit contra la deriva racista i xenòfoba, que, encara avui, segueix existint i estenent-se perillosament per tota la Unió Europea. I, també, contra la manca de reacció o la tèbia i oportunista intervenció dels governs europeus.

Contra l'estereotip, d'entrada ha de quedar clar que el conjunt dels gitanos no són lladres, ni són perillosos i violents; com tampoc el conjunt dels paios abandonen els seus majors en asils i residències, ni són egoistes amb la família. ${ }^{10}$ Cal exigir a tothom el respecte als drets humans i, amb la mateixa vehemència, el compliment,

8 Le Goff, J. (1983): Tiempo, trabajo y cultura en el occidente medieval. Barcelona, Taurus. Sobre la construcció social i històrica del temps: Iglesias de Ussel, J. (1987): El tiempo en la sociedad contemporánea. En Política y Sociedad. Estudios en homanaje a Francisco Murillo Ferrol. (vol. 1). Madrid, CIS/CES.

9 San Román, T. (1996): Los muros de la separación. Ensayo sobre alterofobia y filantropía. Madrid-Bellaterra (Barcelona), Tecnos - Servei de Publicacions UAB, pp. 17-101.

10 Sobre els estereotips: San Román, T., Garriga, Carmen (1975): La imagen paya de los gitanos. Revista de Treball Social. (Barcelona) núm.60, pp. 26-41. 
per part de tots, dels deures cívics comuns; condemnar l'expulsió indiscriminada i massiva de famílies senceres de gitanos i, alhora, exigir, de tots els ciutadans per igual, el respecte de les lleis i de les normes de convivència que permeten viure juntes persones amb cultures, amb formes de vida, costums i tradicions diverses. Tots tenim drets $i$ tots tenim deures a complir envers els nostres veïns. Les «solucions» dràstiques, expeditives i indiscriminades són el camí segur cap a una inseguretat ciutadana més gran i un increment de la conflictivitat social, primer latent i després manifesta, en les relacions interculturals. Les solucions que es necessiten són les de la convivència, la paciència i la negociació. Són solucions difícils, és cert, demanen temps i la complicitat del conjunt de la població, amb un projecte ciutadà compartit i exigent amb tothom per igual. El camí no pot ser un altre que el del respecte mutu i el de les normes de convivència exigides per igual a tothom. No em resisteixo a reproduir un lúcid pensament de Josep Maria Terricabras:

És imprescindible avançar en la pràctica del diàleg intercultural, és a dir, en el diàleg de les diferències i de les semblances que, amb formes i matisos infinits, van creant un riquísim entramat de relacions entre nosaltres»; [tendint a] «eliminar les desigualtats, sense eliminar les diferències. Perquè el camí que porta a la justícia és el que avorreix la desigualtat, però coneix i valora la diferència [...]. Només el diàleg i la cooperació entre persones diferents pot ajudar a aconseguir que aquestes persones es trobin cada dia en situacions menys desiguals.

[...] Haurem d'aprendre també a viure amb el conflicte: no només amb la gestió del conflicte, sinó -si se'm permet l'expressió- amb la indigestió del conflicte. Fins que la indigestió, és clar, no condueixi a la destrucció social. Em refereixo només a la necessària paciència que requereix qualsevol conflicte, i a la grandiosa paciència histórica que requereix un conflicte intercultural. Si parlem d'històries paral-leles de cents i milers d'anys, no podem pensar que aquestes històries arribin a convergir tranquil-lament en pocs anys.

[...] L'exercici de la paciència, de l'acceptació col-lectiva de la impossibilitat de resoldre un determinat conflicte podria ser una nova forma de tolerància provisional que ajudés precisament a encaminar la solució posterior del problema; així com la tolerància no és indiferència, tampoc la paciència és resignació. ${ }^{11}$

Sincerament, prendre el «carrer del mig» no porta enlloc, ni als gitanos ni als no gitanos (paios). Ja ho deia un vell proverbi gitano, recollit per Antonio Machado:

Conversación de gitanos:

- Para rodear

toma la calle de en medio;

nunca llegarás.

11 Terricabras, J. Ma (1996): Tolerància i gestió del conflicte intercultural. A F. Carbonell (coord.): Sobre Interculturalitat 3. Girona, Fundació Sergi, pp. 193-199. 